\title{
JPEB
}

Jurnal Penelitian Ekonomi dan Bisnis, 3 (2), 2018, Hal: 61 - 72

http://www.jpeb.dinus.ac.id

\section{PENGARUH KEPEMIMPINAN DAN BUDAYA KERJA TERHADAP KINERJA TENAGA KEPENDIDIKAN DENGAN MOTIVASI KERJA SEBAGAI VARIABEL INTERVENING (STUDI PADA UNIVERSITAS ISLAM NEGERI WALISONGO SEMARANG)}

\author{
Ali Shodikin* \\ Magister Manajemen, Fakultas Ekonomi dan Bisnis,Universitas Dian Nuswantoro \\ Jalan Imam Bonjol Nomor 207 Semarang 50131, Indonesia \\ *Corresponding Email : aliz12284@gmail.com
}

Diterima: April 2018; Direvisi: Juli 2018; Dipublikasikan: September 2018

\begin{abstract}
This study is to examine the effect of leadership and work culture on employee performance through motivation of work of educational staff at Walisongo State Islamic University Semarang. The population in this study were all educational staff with 186 people, but only 127 observations could be analyzed. This research method uses surveys with primary data collected using a questionnaire. The analysis technique used is multiple linear regression. The results of the study found that of the five hypotheses proposed, three hypotheses were rejected, so that only two hypotheses were accepted. Leadership and motivation were found to have no effect on employee performance, as well as work culture did not affect work motivation. Employee performance is achieved from work culture.
\end{abstract}

Keywords : Leadership; Work Culture; Work Motivation; Performance

\section{ABSTRAK}

Penelitian ini untuk menguji pengaruh kepemimpinan dan budaya kerja terhadap kinerja pegawai melalui motivasi kerja tenaga kependidikan pada Universitas Islam Negeri Walisongo Semarang. Populasi dalam penelitian ini adalah seluruh tenaga kependidikan yang berjumlah 186 orang, namun hanya 127 observasi yang bisa dianalisis. Metode penelitian ini menggunakan survey dengan data primer dikumpulkan menggunakan kuesioner. Teknik analisis yang digunakan adalah regresi linear berganda. Hasil studi menemukan bahwa dari lima hipotesis yang diajukan, ada tiga hipotesis yang ditolak, sehingga hanya ada dua hipotesis yang diterima. Kepemimpinan dan motivasi ditemukan tidak berpengaruh terhadap kinerja pegawai, demikian juga budaya kerja tidak berpengaruh terhadap motivasi kerja. Kinerja pegawai dicapai dari budaya kerja.

Kata Kunci : Kepemimpinan; Budaya Kerja; Motivasi Kerja; Kinerja 


\section{PENDAHULUAN}

Universitas Islam Negeri Walisongo merupakan sebuah Universitas yang di bawah wewenang Kementerian Agama sesuai dengan Peraturan Menteri Agama RI Nomor 16 Tahun 2016 tentang Organisasi dan Tata Kerja Kementerian Agama RI yang merupakan Universitas yang berada dan bertanggung jawab kepada Menteri agama RI, yang mempunyai tugas melaksanakan tugas pemerintah di bidang pendidikan (Kementerian Agama RI, 2016). Untuk melaksanakan tugas dan fungsi dibidang pendidikan tersebut oleh Kementerian Agama RI dikeluarkan Peraturan Menteri Agama RI Nomor 54 Tahun 2015 tentang Organisasi dan Tata Kerja Universitas Islam Negeri Walisongo Semarang (Kementerian Agama RI, 2016).

Untuk melaksanakan tugas tersebut, sistem/pelayanan pendidikan yang ada harus mengacu pada Keputusan Menteri Pendayagunaan Aparatur Negara Nomor 63/KEP/M.PAN7/2003 Tentang Pedoman Umum Penyelenggaraan Pelayanan Publik, yang disebut pelayanan publik adalah segala kegiatan pelayanan yang dilaksanakan oleh penyelenggara pelayanan publik sebagai upaya pemenuhan kebutuhan penerima layanan maupun pelaksanaan ketentuan peraturan perundang-undangan, dan telah dijabarkan oleh Kementerian Agama RI dalam Peraturan Menteri Agama RI Nomor 168 Tahun 2010 tentang Pedoman Penyusunan Standar Pelayanan Operasional di lingkungan Kementerian Agama RI (Kementerian Agama RI, 2010).

Sebagai bentuk pedoman penyusunan operasional prosedur di lingkungan Kementerian Agama adalah untuk mendorong penyelenggaraan pemerintah yang lebih efektif, efisien dan akuntabel. Pemerintah telah mencanangkan penerapan prinsip-prinsip penyelenggaraan tata kelola kepemerintahan yang baik dan bersih (good governance and clean government) melalui penerapan reformasi birokrasi, yang secara umum ditujukan untuk meningkatkan pelayanan kepeda masyarakat. Secara operasional wujud peningkatan kualitas pelayanan kepada masyarakat adalah berupa perbaikan dan penyempurnaan proses penyelenggaraan administrasi pemerintah sehingga lebih mencerminkan birokrasi yang mampu menjalankan fungsi pelayanan umum yang berkualitas, memuaskan, transparan, dan dapat dipertanggungjawabkan.

Komitmen untuk memajukan dan mengembangkan UIN Walisongo Semarang telah dibangun semenjak tenaga kependidikan bekerja dan terus mengalami peningkatan seiring dengan bervariasinya pekerjaan. Hal ini menunjukkan bahwa rata-rata tenaga kependidikan mempunyai penghayatan yang tinggi terhadap budaya kerja Islam, karena dalam budaya kerja Islam terdapat sikap dan pandangan yang mengacu pada peningkatan kualitas SDM (Sumber Daya Manusia). Kenyataannya secara mendasar UIN Walisongo Semarang dalam memberikan pelayanan yang optimal kepada masyarakat terdapat sebuah kendala yang mendasar yaitu: kepemimpinan, budaya kerja, kinerja tenaga kependidikan, dan motivasi dari pimpinan.

Dalam meningkatkan motivasi tenaga kependidikan diperlukan seorang pemimpin yang mampu mengerahkan tenaga kependidikan dengan baik, yang berdasarkan syari'ah Islam. Alasan inilah yang melatarbelakangi penulis untuk mengambil topik penelitian mengenai pengaruh kepemimpinan terhadap kinerja tenaga kependidikan.Tertanamnya budaya kerja yang telah telah mengakar di UIN Walisongo Semarang menjadikan spirit tenaga kependidikan semakin tinggi dalam bekerja. Hal ini disebabkan banyak tenaga kependidikan yang menunaikan ibadah berjama'ah di masjid, sehingga memicu para tenaga kependidikan untuk bisa seperti yang lainnya. Sebagai Instituti yang kental dengan nuansa, UIN Walisongo Semarang memiliki berbagai bentuk kegiatan yang bernuansa. Kegiatan tersebut antara lain: 1). Kajian Kitab Kuning setiap Senin dan Kamis, 2). Pengajian pada peringatan hari besar Islam, 3). Istighosah setiap memasuki tahun ajaran baru. Motivasi kerja sangat penting untuk meningkatkan kualitas sumber daya manusia dalam institusi, terutama dalam UIN Walisongo Semarang sangat mengandalkan sumber daya manusia sebagai poros untuk menjalankan kegiatannya, oleh karena itu sumber daya manusia dalam isntitusi wajib memiliki motivasi 
Ali Shodikin : Pengaruh Kepemimpinan Dan Budaya Kerja Terhadap Kinerja TenagaKependidikan Dengan Motivasi Kerja Sebagai Variabel Intervening(Studi Pada Universitas Islam Negeri Walisongo Semarang)

kerja untuk menghasilkan kinerja yang memuaskan. Adapun bentuk motivasi tersebut antara lain: 1). Diberikannya tunjangan kinerja lebih tinggi terhadap tenaga kependidikan yang memiliki kinerja baik, 2). Hukuman dalam bekerja (berat, ringan dan sedang). Kinerja tenaga kependidikan di UIN Walisongo Semarang mengacu pada prestasi yang diukur berdasarkan standar atau kriteria yang ditetapkan oleh instituti. Setiap tenaga kependidikan diberikan sebuah motivasi untuk menghasilkan pekerjaan selama satu tahun kemudian hasil atau prestasi kerja tersebut di berikan imbalan sebuah tunjangan yang telah di tentukan oleh institusi.

Peneliti mengadakan penelitian pada UIN Walisongo Semarang, karena selama ini masih sangat terbatasnya penelitian mengenai kepemimpinan islami, budaya kerja islami dan motivasi kerja dalam kinerja tenaga kependidikan. Kinerja tenaga kependidikan diharapkan semakin meningkat di UIN Walisongo Semarang, dengan upaya terus menerus ditingkatkan agar bisa bertahan dan juga bisa berkembang bahkan bisa semaksimal mungkin. Berdasarkan kepentingan tersebut maka penulis mengambil tema ini.

\section{TINJAUAN PUSTAKA \\ Kepemimpinan}

Banyak definisi yang menjelaskan tentang kepemimpinan, tetapi secara mendasar biasa dikenal dengan sebutan "Leadership" yang berarti mempengaruhi orang. Sebagian besar orang menganggap pemimpin sebagai sumber pengaruh, karena pada dasarnya seorang pemimpin mempengaruhi para pengikut atau sebagai pihak yang dipengaruhi (Riva'i, 1974). Istilah kepemimpinan di dalam Al-Qur'an ialah : Pertama, Khalifah, merupakan pemimpin yang memikul amanah dan tanggung jawab untuk melaksanakan pemerintahan dan menegakkan kebenaran (Mohamad, Abdullah, \& Adnan, 2012), (Al-Qur'an, Surah Shaad, 38: 26), kedua, Imam, sebagai pemimpin yang menjalankan tugas berdasarkan petunjuk Allah (Mohamad, Abdullah, \& Adnan, 2012), (Al-Qur'an, Surah Al-Anbiya: 73), ketiga, Malik, sebagai pemimpin yang berperang dan berjuang menegakkan agama Allah (Mohamad, Abdullah, \& Adnan, 2012), (Al-Qur'an, Surah Al-Baqarah: 246), dan keempat, Tankin, perkataan ini digunakan oleh Al-Qur'an untuk menunjukkan bahwa kekuasaan dan pengaruh telah diberikan kepada para pemimpin seperti Zulkarnain, Nabi Yusuf di Mesir, Nabi Muhammad SAW, golongan ulama dan sebagainya. Kuasa itu diberikan untuk mendaulatkan ajaran Allah (Mohamad, Abdullah, \& Adnan, 2012).

Beberapa pengertian kepemimpinan menurut pandangan Islam seperti di atas semuanya memaknai bahwa kepemimpinan Islam merupakan kepemimpinan menurut cara-cara Islam dan mencapai suatu tujuan atas Izin dan Ridha Allah SWT. Sedangkan yang dimaksud kepemimpinan dalam konteks studi ini adalah kegiatan menuntun, membimbing, memandu jalan yang diridhoi Allah SWT. Jadi kepemimpinan disini semata-mata hanya mencari atau melakukan kegiatan sesuai jalan yang diridhoi Allah SWT.

Menurut Rifai dan Arifin (2009) sebagai seorang pemimpin harus berpegang teguh pada Al-Qur'an dan Hadits dan harus mempunyai empat sifat yang dimiliki oleh para pemimpin sebagai berikut: (1) Ash-Shidq (kebenaran), artinya seorang pemimpin harus mampu bersikap, berucap serta berjuang melaksankan tugasnya, (2) Al-Amanah (kepercayaan), artinya seorang pemimpin mampu menjadikan dia memlihara sebaik-baiknya apa yang diserhakan kepadanya baik dari Tuhan maupun dari orang-orang yang dipimpinnya, (3) Al-Fathanah (kecerdasan), yang berarti bahwa pemimpin harus selalu siap menghadapi dan menanggulangi persoalan yang muncul seketika mungkin, dan (4) At-Tabligh (jujur), yang artinya bahwa seorang pemimpin harus terbuka kepada siapapun dan bertanggungjawab.

Peran penting kepemimpinan dalam Islam, yaitu:1). Pemimpin harus fleksibel dan mempunyai pengalaman yang luas; 2). Menganggap tanggung jawab "seremonial" atau "spiritual" sebagai epala organisasi/perusahaan menjadi suatu fungsi yang diperlukan, bukan 
suatu hal yang remeh yang harus dialami atau didelegasikan kepada orang lain; 3). Pembuatan tidak dibuat secara efektif terpusat di puncak organisasi (Rivai, dkk, 2009). Berdasarkan peran kepemimpinan menurut pandangan Islam di atas, dapat disimpulkan bahwa peran penting kepemimpinan menurut pandangan Islam ialah peran pemimpin yang akan membawa organisasi menuju sistem Islam yang semestinya diterapkan.

\section{Budaya Kerja}

Budaya kerja stabil dari waktu ke waktu, tetapi tidak pernah statis (Robbins, 1998). Budaya kerja terdiri atas otonomi individu, struktur, dukungan, identitas, penghargaan kinerja, toleransi konflik, dan toleransi risiko. Budaya kerja Islam haruslah bermotivasikan, dinamisme dan memupuk sifat dinamik untuk memimpin. Pekerja akan menyadari potensi dan kekuatan yang dikaruniakan Allah kepadanya seperti daya cipta, akal, pemkikiran asli, bakat yang tersendiri, kemampuan menggunakan alat-alat tertentu dan sebagainya. Itulah yang dinamakan budaya kerja dalam persepektif Islam (Ahlami, 2003).

Budaya kerja umat Islam dalam menghadapi masa globalisasi saat ini, banyak perusahaan yang mengadopsi budaya-budaya asing karena diyakini begitu maju dan berkembang. Budaya asing tidak selamanya negatif maupun positif, dengan catatan sesuai dengan Islam. Budaya penghargaan atas waktu dan ketepatan dalam memenuhi janji, selalu dianggap sebagai budaya asing, padahal itu adalah bagian dari ajaran Islam (Hafinuddin, Didin dan Tanjung, Hendri, 2003).

Budaya kerja Islam berarti mengaktualisasikan seluruh potensi iman, pikir, dan zikir, serta keilmuan kita untuk memberikan nilai kebahagiaan. Inti atau sumber inspirasi budaya Islam adalah Al-qur'an dan sunnah Rasululllah SAW, yang diikat dalam satu kata, yaitu akhlak. Dalam Islam, manusia dituntut untuk minta tolong pada Allah dan mengakui keterbatasan dirinya. Allah lebih mencintai orang-orang yang selalu meminta daripada yang enggan meminta, karena seolah-olah manusia itu berkecukupan.

Firman Allah SWT: (QS. Al-Mu'min:60)

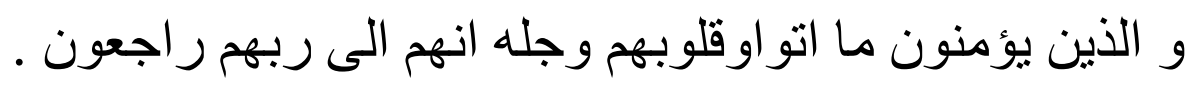

Artinya: "Berdoalah kepada-Ku, niscaya akan Kuperkenankan bagimu. Sesungguhnya orang-orang yang menyombong-kan diri dari menyembah-Ku akan masuk neraka Jahannam dalam keadaan hina" (Departemen Agama RI, 1989).

Apabila manusia rajin bekerja dan berupaya, ia akan menciptakan budaya kerja yang disiplin, keras kemauan dan tidak cepat putus asa. Sementara itu, individu itu terus menerus berdo'a dan meminta tolong dan ridho-Nya, agar usahanya membuahkan hasil. Sifat ini akan membawa manusia ke perilaku rendah hati, takut, takabur dan senantiasa menyadari baik kelemahan maupun kekuatannya. Dalam bukunya Hafinuddin, D. dan Tanjung, H. (2003), mengatakan bahwa penghayatan terhadap nilai atau makna hidup, agama, pengalaman dan pendidikan harus diarahkan untuk menciptakan sikap kerja professional, sedangkan apresiasi nilai yang bersifat aplikatif akan membuahkan akhlakul karimah, diantaranya: Ash-Sholeh (Baik dan bermanfaat), Al-Itqon (Kemantapan), Al- Ihsan (Melakukan yang Terbaik atau Lebih Baik Lagi), Al-Mujahadah (Kerja Keras dan Optimal), Tanafus dan Taawun (Berkompetisi dan Tolong Menolong), dan Sifat (Shiddiq, Istiqomah, Fathanah, Amanah, dan Tabligh).

\section{Motivasi Kerja}

Motivasi setiap orang atau karyawan berbeda-beda tergantung yang melatarbelakangi. Namun dasarnya motivasi akan mempengaruhi prestasi dan produktivitas kerja karyawan sendiri. Dalam bukunya yang berjudul Bekerja dengan Hati Nurani, Akh. Muwafik Saleh 
Ali Shodikin : Pengaruh Kepemimpinan Dan Budaya Kerja Terhadap Kinerja TenagaKependidikan Dengan Motivasi Kerja Sebagai Variabel Intervening(Studi Pada Universitas Islam Negeri Walisongo Semarang)

(2009), mengatakan selama ini, banyak orang bekerja untuk mengajar materi belaka demi kepentingan duniawi, mereka tak sedikitpun memerdulikan kepentingan akhirat kelak. Oleh karena itu sudah saatnya para pekerja bekerja dengan motivasi yang dapat memberikan kepribadian yang baik dan dibenarkan oleh Islam yang harus memenuhi ciri-ciri sebagai berikut (Muwafik Saleh, 2009): Niat Baik dan Benar (Mengharap Ridha Allah SWT), Takwa Dalam Bekerja, dan Ikhlas Dalam Bekerja.

Motivasi dalam perspektif Islam menurut Abdul Hamid Mursi, dalam bukunya yang berjudul SDM yang produktif pendekatan Al- Qur'an dan sains, bahwa motivasi menpunyai konsep pokok sebagai berikut (Abdul Hamid Mursi, 1997): Motivasi Fisiologis, Motivasi Psikologis atau Sosial, dan Motivasi Bekerja dan Berproduksi. Salah satu perbedaan yang paling esensial mengenai teori motivasi atau kebutuhan antara teori yang dikemukakan oleh para penulis Barat dan Islam adalah dalam faktor keimanan (faith) yang melandasi semua aktivitas manusia dan memotivasinya untuk bekerja. Teori - teori kebutuhan yang dikemukakan oleh penulis Barat mendapat kritikan dari ajaran-ajaran agama Timur. Salah satu kekurangan fatal teori-teori tersebut adalah mereka hanya melihat manusia sebagai makhluk materi semata. Salah satu wujudnya dengan menerapkan sistem waktu adalah uang, padahal manusia adalah makhluk yang berdimensi ganda, disamping sebagai makhluk yang mempunyai unsur materi, manusia juga merupakan makhluk spiritual, atau menurut istilah lain manusia adalah terdiri dari jasmani dan rohani.

\section{Kinerja}

Kinerja dapat diartikan sebagai hasil kerja yang dapat dicapai oleh seseorang atau sekelompok orang dalam suatu organisasi, sesuai dengan wewenang dan tanggungjawab masing-masing, dalam rangka upaya mencapai tujuan organisasi bersangkutan secara legal, tidak melanggar hukum dan sesuai dengan moral dan etika (Suryadi, P., 1999). Pengukuran terhadap kinerja perlu dilakukan untuk mengetahui apakah selama pelaksanaan kinerja terdapat deviasi dari rencana yang telah ditentukan atau apakah hasil kinerja telah tercapai sesuai dengan yang diharapkan. Pengukuran kinerja dapat dilakukan dengan cara:

1. Memastikan bahwa persyaratan yang diinginkan pelanggan telah terpenuhi.

2. Mengusahakan standar kinerja untuk menciptakan perbandingan.

3. Pertimbangan penggunaan sumber daya.

4. Menetapkan arti penting masalah kualitas dan menentukan apa yang perlu prioritas perhatian.

5. Perencanaan kerja.

Sedangkan Kreitner, R. dan Kinicki, A. (2003) mengatakan bahwa untuk melakukan pengukuran kinerja perlu memenuhi persyaratan diantaranya:

1. Dalam posisi mengamati perilaku kinerja yang menjadi kepentingan individu.

2. Mampu memahami tentang dimensi atau gambaran kinerja.

3. Mempunyai pemahaman tentang format skala dan instrumennya.

4. Harus termotivasi untuk melakukan pekerjaan secara sadar.

Menurut Bernardin dan Russel dalam Kokasih, N. (2007)terdapat beberapa kriteria untuk menilai karyawan yang bemanfaat dalam pengukuran kinerja karyawan, yaitu:

1. Quality: Tingkatan dimana proses atau penyesuaian pada cara yang ideal didalam melakukan aktivitas atau memenuhi aktivitas sesuai harapan.

2. Quantity: Jumlah yang dihasilkan diwujudkan melalui nilai mata uang atau jumlah dari siklus aktivitas yang telah diselesaikan.

3. Timelines: Tingkatan dimana aktivitas telah diselesaikan dengan waktu yang telah ditentukan dan memaksimalkan waktu untuk aktivitas lain.

4. Cost Effectiveness: Tingkatan dimana penggunaan sumber daya perusahaan berupa manusia, keuangan, teknologi di maksimalkan untuk mendapat hasil yang tinggi.

5. Interpersonal Impact: Tingkatan dimana seorang karyawan merasa percaya diri, punya 
keinginan yang baik, dan bekerja sama diantara rekan kerja.

\section{Pengembangan Hipotesis}

1. Hubungan Kepemimpinan dan Motivasi Kerja

G.R.Terry dalam Sutarto (1995) dalam bukunya "Principle of Management" mengatakan bahwa kepemimpinan adalah kegiatan mempengaruhi orang-orang agar mereka suka berusaha mencapai tujuan-tujuan kelompok. Robnagel, C.S. (2016) menyatakan para pemimpin menunjukkan jalan dan membantu karyawan mengejarnya dengan memberdayakan dan melibatkan para karyawan tersebut (Gill, 2012) melalui "kemampuan ... untuk memengaruhi, memotivasi, dan memungkinkan orang lain untuk berkontribusi terhadap efektivitas dan keberhasilan organisasi". Studi-studi yang mendukung konsep ini adalah Naile, I. \&Selesho, J.M. (2014), Rawung, F.H. (2013), dan Rahbi, D.A. et al. (2017), yang menemukan bahwa variabel kepemimpinan berpengaruh signifikan terhadap variabel motivasi kerja. Berdasarkan uraian diatas maka dapat disusun hipotesis 1 sebagai berikut:

$\mathrm{H}_{1}$ : Kepemimpinan berpengaruh Positif terhadap Motivasi Kerja.

\section{Hubungan Budaya Kerja dan Motivasi Kerja}

Budaya kerja dapat membantu kerja karyawan, karena menciptakan suatu tingkat motivasi yang luar biasa bagi karyawan untuk memberikan kemampuan terbaiknya dalam memanfaatkan kesempatan yang diberikan oleh organisasinya. Nilai-nilai yang dianut bersama membuat karyawan merasa nyaman bekerja, memiliki komitmen dan kesetiaan serta membuat karyawan berusaha lebih keras, meningkatkan kerja dan kepuasan kerja karyawan, serta mempertahankan keunggulan kompetitif. Hubungan ini didukung oleh studi-studi yang dilakukan oleh Engin, M. \& McKeown, K. (2012). Hasan, A.R. \& Hynds, A. (2014), dan Mustajbasic, E. \& Huzakovic, D. (2016) menemukan bahwa budaya kerja memberikan pengaruh signifikan terhadap motivasi kerja. Berdasarkan uraian diatas maka dapat disusun hipotesis 2 sebagai berikut:

$\mathrm{H}_{2}$ : Budaya Kerja berpengaruh Positif terhadap Motivasi Kerja.

\section{Hubungan Kepemimpinan dan Kinerja}

Kepemimpinan merupakan kemampuan untuk mempengaruhi pihak lain. Keberhasilan seorang pemimpin tergantung kepada kemampuannya untuk mempengaruhi itu. Dengan kata lain kepemimpinan dapat diartikan sebagai kemampuan seseorang untuk mempengaruhi orang lain, melalui komunikasi baik langsung maupun tidak langsung dengan maksud untuk menggerakkan orang-orang tersebut agar dengan penuh pengertian, kesadaran dan senang hati bersedia mengikuti kehendak pemimpin. Seorang pemimpin yang efektif adalah seorang yang memiliki kemampuan tersebut. Menurut Tandoh (2011) penelitian menemukan bahwa jika gaya atau perilaku yang berpusat pada pekerjaan ditunjukkan oleh pemimpin atau manajer memiliki efek positif pada kinerja karyawan. Hal ini berarti bahwa manajer secara khusus bertujuan untuk mendapatkan hasil dan hanya dengan memotivasi karyawan untuk memberikan yang terbaik dalam meningkatkan produktivitas. Namun, juga diamati bahwa gaya kepemimpinan yang berpusat pada karyawan sangat sedikit atau minimal yang diperlihatkan dan ini berdampak negatif terhadap kinerja. Ini mungkin menunjukkan bahwa manajemen bertindak dengan aturan internal yang ketat untuk mencapai hasil dan fakta bahwa praktek ini juga tidak menguatkan gaya berpusat demokratis. Studi yang mendukung hubungan ini adalah Pradeep, D.D. \& Prabhu, N.R.V. (2011), Abdulahi Ali, A.S. et al. (2013), dan Thompson, K. \& Webber, J.K. (2016) menemukan bahwa kepemimpinan berpengaruh signifikan positif terhadap kinerja. Berdasarkan uraian diatas maka dapat disusun hipotesis 3 sebagai berikut:

$\mathrm{H}_{3}$ : Kepemimpinan berpengaruh Positif terhadap Kinerja. 
Ali Shodikin : Pengaruh Kepemimpinan Dan Budaya Kerja Terhadap Kinerja TenagaKependidikan Dengan Motivasi Kerja Sebagai Variabel Intervening(Studi Pada Universitas Islam Negeri Walisongo Semarang)

4. Hubungan Budaya Kerja dan Kinerja

Dalam upaya pencapaian hasil kinerja karyawan yang optimal, suatu organisasi biasanya membentuk suatu upaya strategis dalam membenahi kinerja karyawannya, oleh sebab itu diperlukan adanya suatu perubahan atmosfir kerja berupa perubahan paradigma atau cara pandang, pola pikir, dan cara bertindak dalam menjalankan kegiatan operasional organisasi. Dengan demikian, program transformasi kultural di suatu organisasi dapat berjalan dengan baik. Adapun suatu organisasi yang telah menjalankan hal tersebut akan memiliki ciriciri perubahan yang bersifat sangat mendasar, strategis, dan menyeluruh sehingga tujuan yang telah ditetapkan dalam bentuk visi dan misi dapat terlaksana. Hal ini mendukung studi yang dilakukan oleh Paschal, A.O. \& Nizam, I. (2016), Wanjiku, N.A. \& Agusioma, N.L. (2014) and Narayana, A. (2017). Berdasarkan uraian diatas maka dapat disusun hipotesis 4 sebagai berikut:

$$
\mathrm{H}_{4} \text { : Budaya Kerja berpengaruh Positif terhadap Kinerja. }
$$

5. Hubungan Motivasi Kerja dan Kinerja

Teori pengharapan dari Victor Vroom dalam Robbins (2006) memberikan suatu pernyataan tentang adanya suatu hubungan antara motivasi dan kinerja, pernyataan tersebut sebagai berikut: "Bahwa seorang karyawan akan bersedia melakukan upaya yang lebih besar apabila diyakininya bahwa upaya itu akan berakibat pada penilaian kinerja yang baik, dan bahwa penilaian kinerja yang baik akan berakibat pada kenaikan gaji serta promosi, dan kesemuanya itu memungkinkan yang bersangkutan untuk mencapai tujuan pribadinya. Mohamud, S.A., et al. (2017), Bao, C. \& Nizam, I. (2015), dan Shahzadi, I., et al. (2014) menemukan bahwa motivasi kerja berpengaruh positif dan signifikan terhadap kinerja pegawai. Berdasarkan uraian diatas maka dapat disusun hipotesis 5 sebagai berikut:

$\mathrm{H}_{5}$ : Motivasi Kerja berpengaruh Positif terhadap Kinerja.

\section{METODE PENELITIAN}

Populasi yang dijadikan sebagai objek dalam penelitian ini adalah seluruh Pegawai Negeri Sipil tenaga Kependidikan Universitas Islam Negeri Walisongo Semarang, sebanyak 186 orang dan semua dijadikan responden studi ini. Pengukuran variabel kepemimpinan dengan menggunakan 4 item (Rifa'i dan Arifin, 2009), budaya kerja menggunakan 6 item (Hafinuddin, D. \& Tanjung, H. (2003), motivasi kerja menggunakan 3 item (Akh. Muwafik Saleh, 2009), dan kinerja pegawai menggunakan 4 item yang diadopsi (Robert L. Mathis-John H. Jackson, 2006). Pengujian instrumen penelitian untuk validitas menggunakan analisis faktor dan reliabilitas menggunakan alpha cronbach.Analisis data dilakukan dengan menggunakan analisis regresi berganda.

\section{HASIL DAN PEMBAHASAN \\ Deskripsi Responden}

Responden dalam studi ini sejumlah 127 orang, yang terdiri dari laki-laki sebanyak 70 orang sedangkan perempuan sebanyak 57orang. Kualifikasi pendidikan mereka terdiri dari S. 2 dengan jumlah 27 orang, S.1 dengan jumlah 30 orang, SMA dengan jumlah 35 orang, SMP dengan jumlah 25 dan sedangkan SD berjumlah 10 orang.

\section{Deskripsi Variabel}

Deskripsi untuk empat variabel yang digunakan dalam studi ini dipaparkan untuk mean, standar deviasi, dan korelasi yang disajikan pada Tabel 1. Deskripsi Variabel Penelitian berikut: 
Tabel 1. Deskripsi Variabel Penelitian

\begin{tabular}{lcccccc}
\hline \multicolumn{1}{c}{ Variabel } & Means & SD & Kepemimpinan & $\begin{array}{c}\text { Budaya } \\
\text { Kerja }\end{array}$ & $\begin{array}{c}\text { Motivasi } \\
\text { Kerja }\end{array}$ & Kinerja \\
\hline Kepemimpinan & 5,321 & 0,671 & & & & \\
Budaya Kerja & 5,453 & 0,873 & 0,124 & & & \\
Motivasi Kerja & 4,543 & 0,756 & 0,425 & 0,102 & & \\
Kinerja & 5,675 & 0,857 & 0,221 & 0,467 & 0,198 & \\
\hline
\end{tabular}

\section{Uji Instrumen}

Hasil pengujian instrumen untuk validitas disajikan pada Tabel 2. Uji Validitas berikut:

Tabel 2. Uji Validitas

\begin{tabular}{lccc}
\hline Variabel & Indikator & Loading & Keterangan \\
\hline Kepemimpinan & X1.1 & 0,749 & Valid \\
Reliabilitas: 0,874 & X1.2 & 0,868 & Valid \\
& X1.3 & 0,907 & Valid \\
X1.4 & 0,915 & Valid \\
Budaya Kerja & X2.1 & 0,764 & Valid \\
Reliabilitas: 0,946 & X2.2 & 0,926 & Valid \\
& X2.3 & 0,939 & Valid \\
& X2.4 & 0,949 & Valid \\
& X2.5 & 0,872 & Valid \\
Motivasi Kerja & X2.6 & 0,964 & Valid \\
Reliabilitas: 0,821 & Y1.1 & 0,739 & Valid \\
& Y1.2 & 0,937 & Valid \\
Kinerja & Y1.3 & 0,923 & Valid \\
Reliabilitas: 0,886 & Y2.1 & 0,849 & Valid \\
& Y2.2 & 0,778 & Valid \\
& Y2.3 & 0,942 & Valid \\
& Y2.4 & 0,945 & Valid \\
\hline
\end{tabular}

Berdasarkan Tabel 2. Uji Validitas ditemukan bahwa pengujian instrumen untuk validitas diperoleh nilai bahwa semua indikator dalam studi ini valid. Variabel kepemimpinan menghasilkan nilai berkisar dari 0,749-0,915, budaya kerja memberikan nilai 0,764-0,949, motivasi kerja memiliki nilai berkisar 0,739-0,937, dan variabel kinerja pegawai memberikan nilai berkisar 0,778-0,945. Adapun nilai reliabilitas memberikan nilai berkisar dari 0,8210,946, maka dapat disimpulkan bahwa semua variabel dalam studi ini reliabel.

\section{Hasil Analisis}

Hasil analisis data dengan menggunakan regresi linear berganda disajikan pada Tabel 3. Hasil Analisis Data berikut: 
Ali Shodikin : Pengaruh Kepemimpinan Dan Budaya Kerja Terhadap Kinerja TenagaKependidikan Dengan Motivasi Kerja Sebagai Variabel Intervening(Studi Pada Universitas Islam Negeri Walisongo Semarang)

Tabel 3. Hasil Analisis Data

\begin{tabular}{lllllll}
\hline $\begin{array}{l}\text { Variabel } \\
\text { Independen }\end{array}$ & \multicolumn{2}{l}{ Model 1 (Dependen: Motivasi) } & $\begin{array}{l}\text { Model } \\
\text { Kinerja) }\end{array}$ & 2 & (Dependen: \\
\cline { 2 - 7 } & Koefisien & t-hitung & Sign & Koefisien & t-hitung & Sign \\
\hline Kepemimpinan & 0,345 & 4,049 & 0,000 & 0,161 & 1,747 & 0,08 \\
Budaya Kerja & 0,132 & 1,552 & 0,123 & 0,258 & 2,947 & 0,00 \\
Motivasi Kerja & & & & 0,057 & 0,625 & 0,53 \\
& & & & & & 3 \\
F & 11,723 & & & 0,160 & & \\
Sign F & 0,000 & & & 0,001 & & \\
Adj $\mathrm{R}^{2}$ & 0,145 & & & 0,109 & & \\
\hline
\end{tabular}

Studi menemukan bahwa dari lima hipotesis yang diuji, ada tiga hipotesis yang ditolak, sehingga hanya ada dua hipotesis yang diterima. Hipotesis yang ditolak adalah bahwa budaya kerja tidak berpengaruh terhadap motivasi kerja pegawai dengan nilai signifikansi sebesar $0,123(>0,05)$, kepemimpinan tidak berpengaruh terhadap kinerja pegawai dengan nilai signifikansi 0,083 (>0,05), serta motivasi ditemukan juga tidak berpengaruh terhadap kinerja pegawai dengan nilai signifikansi sebesar 0,533 (>0,05). Dua model dalam studi ini juga menunjukkan fit yang jelek, karena kemungkinan kurang tepatnya faktor-faktor yang dipilih peneliti dalam menjelaskan kinerja pegawai kependidikan di Universitas Islam Negeri Walisongo Semarang.

\section{Pembahasan}

Kepemimpinan berpengaruh positif terhadap motivasi kerja pegawai di UIN Walisongo Semarang. Hal ini menunjukkan bahwa dengan kepemimpinan yang lebih baik akan meningkatkan motivasi kerja tenaga kependidikan di Universitas Islam Negeri Walisongo Semarang. Dengan demikian dapat dikatakan bahwa peran kepemimpinan yang meliputi mencintai kebenaran dan hanya takut kepada Allah SWT, menjaga amanah dan kepercayaan orang lain, pandai bergaul, memiliki semangat untuk maju dan semangat pengabdian, dan bertanggung jawab dalam mengambil keputusan sangat menentukan motivasi kerja tenaga kependidikan. Hal ini seorang pemimpin sukses dalam mempengaruhi dan memotivasi (attempted leadership) tenaga kependidikan mau mengikuti dan melakukan tindakan yang diperintahkan dengan kesadaran akan manfaat yang ditimbulkan sehingga tujuan Universitas Islam Negeri Walisongo Semarang tercapai. Studi ini mendukung penelitian sebelumnya yang dilakukan oleh Naile, I. \& Selesho, J.M. (2014), Rawung, F.H. (2013), dan Rahbi, D.A. et al. (2017).

Budaya kerja tidak berpengaruh positif terhadap motivasi kerja para pegawai di UIN Walisongo Semarang. Hal ini menunjukkan bahwa peran budaya kerja yang meliputi ashsholeh (baik dan bermanfaat), al-itqan (kemantapan), al-ihsan (melakukan yang terbaik dan lebih baik lagi), al-mujahadah (kerja keras dan optimal), tanafus (berkompetisi), dan ta'awun (tolong menolong) belum mampu meningkatkan motivasi tenaga kependidikan Universitas Islam Negeri Walisongo Semarang. Hal ini menunjukkan bahwa kurangnya kompetisi dalam bekerja dan tolong menolong rendah bukan merupakan penentu dari motivasi kerja para pegawai di lingkungan Universitas Islam Negeri Walisongo Semarang. Studi ini tidak mendukung penelitian sebelumnya yang dilakukan oleh Engin, M. \& McKeown, K. (2012). Hasan, A.R. \& Hynds, A. (2014), dan Mustajbasic, E. \& Huzakovic, D. (2016).

Hasil pengujian yang diajukan dalam penelitian ini bahwa tidak ada pengaruh antara 
kepemimpinan terhadap kinerja tenaga kependidikan. Hal ini menunjukkan bahwa peran kepemimpinan yang meliputi mencintai kebenaran dan hanya takut kepada Allah SWT, menjaga amanah dan kepercayaan orang lain, pandai bergaul, memilki semangat untuk maju dan semangat pengabdian, dan bertanggung jawab dalam mengambil keputusan kurang mampu memberikan dampak bagi kesuksesan dan kefektifan tercapainya tugas yang dilaksanakan oleh tenaga kependidikan Universitas Islam Negeri Walisongo Semarang. Temuan ini juga mengandung makna bahwa siapapun pemimpinnya tidak menjadi masalah bagi tenaga kependidikan, mengingat mereka dalah pegawai-pegawai yang senior yang sudah tahu tugas dan tanggung jawabnya masing-masing. Hasil ini tidak mendukung penelitian sebelumnya oleh Pradeep, D.D. \& Prabhu, N.R.V. (2011), Abdulahi Ali, A.S. et al. (2013), dan Thompson, K. \& Webber, J.K. (2016).

Hasil pengujian yang diajukan dalam penelitian ini bahwa ada pengaruh positif dan signifikan antara budaya kerja terhadap kinerja. Hasil penelitian mendapatkan bahwa budaya kerja di Universitas Islam Negeri Walisongo Semarang sudah dinilai baik, sehingga kondisi kinerja tenaga kependidikan juga semakin dapat cepat dicapai. Hal ini menunjukkan bahwa budaya kerja yang dibangun oleh Universitas Islam Negeri Walisongo Semarang menunjukkan budaya kerja yang kuat, tenaga kependidikan mempunyai etos kerja tinggi, masuk kerja tepat waktu, mempunyai kekompakan dalam bekerja yang sangat kuat. Ini terbukti dengan adanya tugas dan tanggung jawab yang dikerjakan oleh tenaga kependidikan diselesaikan sesuai dengan target sehingga meningkatkan mutu dari kualitas pekerjaan itu sendiri yang berdampak pada kinerja yang optimal. Hasil ini mendukung penelitian sebelumnya oleh Paschal, A.O. \& Nizam, I. (2016), Wanjiku, N.A. \& Agusioma, N.L. (2014) and Narayana, A. (2017).

Hasil pengujian yang diajukan dalam penelitian ini bahwa tidak ada pengaruh motivasi kerja terhadap kinerja. Hal ini menunjukkan bahwa kondisi motivasi dari tenaga kependidikan belum mampu mempengaruhi kinerja tenaga kependidikan. Dengan demikian dapat dikatakan bahwa tenaga kependidikan yang sudah diberi kesempatan untuk mengembangkan dirinya melalui: tugas belajar, mengikuti pendidikan dan latihan kepemimpinan maupun diklat teknis lainnya sebagai bekal memotivasi mereka belum dapat meningkatkan kinerja tenaga kependidikan. Hasil ini tidak mendukung penelitian sebelumnya oleh Mohamud, S.A., et al. (2017), Bao, C. \& Nizam, I. (2015), dan Shahzadi, I., et al. (2014).

\section{SIMPULAN}

Berdasarkan hasil analisis yang telah ditelaah dalam studi ini, maka dapat ditarik kesimpulan bahwa kinerja tenaga kependidikan di Universitas Islam Negeri Walisongo Semarang paling kuat dipengaruhi oleh budaya kerja, hal ini tercermin dari budaya kerja yang selalu mencermati waktu, al-mujahadah (kerja keras dan selalu optimal), al-ihsan (melakukan yang terbaik atau lebih baik lagi) dan memiliki sifat al-itqon (kemantapan diri). Dari empat cermin inilah yang mempunyai pengaruh yang sangat kuat untuk meningkatkan kinerja tenaga kependidikan di Universitas Islam Negeri Walisongo Semarang.Budaya merupakan satusatunya faktor yang meningkatkan kinerja tenaga kependidikan di Universitas Islam Negeri Walisongo Semarang. Karenanya budaya organisasi memainkan peran vital dalam meningkatkan kinerja pegawai. Budaya organisasi harus mengikat semua anggota dan pegawai organisasi karena ini akan mendorong keseragaman di antara anggota organisasi dan ini meningkatkan komitmen, efisiensi kelompok, dan kinerja keseluruhan pegawai kependidikan. Kepemimpinan ditemukan tidak berpengaruh langsung terhadap kinerja tenaga kependidikan, tetapi akan mampu memotivasi kerja. Hal ini berarti pemimpin yang bergantiganti tidak akan berdampak langsung terhadap kinerja tenaga kependidikan, akan tetapi yang akan berpengaruh adalah budaya kerja di Universitas Islam Negeri Walisongo Semarang.

Implikasi kebijakan manajerial yang dapat disampaikan yaitu perlu adanya komitmen 
Ali Shodikin : Pengaruh Kepemimpinan Dan Budaya Kerja Terhadap Kinerja TenagaKependidikan Dengan Motivasi Kerja Sebagai Variabel Intervening(Studi Pada Universitas Islam Negeri Walisongo Semarang)

dan kesungguhan pimpinan dan tenaga kependidikan dalam melaksanakan tugas, agar tercapai kinerja tenaga kependidikan secara optimal, misalnya dengan memberikan peran dan partisipasi yang lebih dan memberikan kepercayaan kepada tenaga kependidikan di UIN Walisongo Semarang. Dalam hal kepemimpinan, bahwa tenaga kependidikan di UIN Walisongo Semarang sangat membutuhkan arahan dan inisiatif dari atasan untuk selalu meningkatkan kinerjanya serta bawahan juga berkeinginan untuk menyumbangkan pikiran dan tenaga untuk UIN Walisongo Semarang, yaitu memberikan saran dan kritikan kepada pimpinan untuk mengembangkan UIN Walisongo Semarang kedepan, keterlibatan seorang tenaga kependidikan di UIN Walisongo Semarang dan partisipasinya sangat diperlukan. Model penelitian yang ditemukan relatif jelek, maka untuk penelitian mendatang diharapkan dengan memperkaya untuk menelaah faktor-faktor yang lebih tepat khususnya untuk yang mengambil obyek pada organisasi yang berbasis agamis, misalnya spiritualitas, karakteristik individu maupun pekerjaan.

\section{DAFTAR PUSTAKA}

Abdulahi Ali, A.S. et al. 2013. The Effect Of Leadership Behaviours On Staff Performance In Somalia. Educational Research International. 2 (2).

Ahlami. 2003. Budaya Kerja Menurut Perspektif Islam diambil dari: http://haslizaali.blogspot.com/2009/12/budaya-kerja-menurut-perspektif-Islam.html.

Al-Qur'anulKarim,Al-Qur'andanTerjemahannya.Bandung:Diponegoro.

Bao, C. \& Nizam, I. 2015. The Impact Of Motivation On Employee Performance In The Electronics Industry In China. International Journal of Accounting \& Business Management. 3 (2).

Engin, M. \& McKeown, K. 2012. Cultural influences on motivational issues in students and their goals forstudying at university. Learning and Teaching in Higher Education: Gulf Perspectives. 9(1).

Gill, R. 2012. Theory and practice of leadership. London: Sage.

Hafinuddin, D. \&Tanjung, H. 2003. Manajemen Syari'ah dalam Praktik, Jakarta: Gema Insani Press.

Hasan, A.R. \& Hynds, A. 2014. Cultural Influence on Teacher Motivation-A Country Study of Maldives. International Journal of Social Science and Humanity. 4 (1).

Kementerian Agama RI. 2010. Pedoman Penyusunan Standar Operasional Prosedur di Lingkungan Kementerian Agama RI Nomor 168.

Kementerian Agama RI. 2016. Organisasi dan Tata Kerja Kementerian Agama RI Nomor 24.

Kementerian Agama RI. 2016. Organisasi dan Tata Kerja UIN Walisongo Semarang Nomor 54.

Kementerian Agama RI. 1996. Al-Qur'an Al-Karim dan Terjemahnya, Semarang: PT Toha Putra.

Kokasih, N. 2007. Pengaruh Knowledge Management Terhadap Kinerja Karyawan (Studi Kasus Departement Front Office Surabaya Plaza Hotel). Jurnal Manajemen. 3 (82).

Kreitner, R. danKinicki, A. 2003.Perilaku Organisasi, alih bahasa Erly Suandy. Jakarta: Penerbit Salemba Empat.

Mohamad, S., Abdullah, A. N., \& Adnan, M. A. 2012. Rahasia kepemimpinan Islam dan kejayaan negara menurut huraian Al-Quran. The 2nd Annual International Qur'anic

Conference. Kuala Lumpur: Centre of Quranic Research Universiti of Malaya.

Mohamud, S.A., et al. 2017. The Effect Of Motivation On Employee Performance: Case Study In Hormuud Company In Mogadishu Somalia. International Journal of Development Research. 7 (11).

Mustajbasic, E. \& Huzakovic, D. 2016. Impact of Culture on Work Motivation: Case of Bosnia and Herzegovina. Journal of Business \& Economic Policy. 3 (3). 
Naile, I. \& Selesho, J.M. 2014. The Role of Leadership in Employee Motivation. Mediterranean Journal of Social Sciences. 5 (3).

Narayana, A. 2017.A Critical Review of Organizational Culture on Employee Performance.American Journal of Engineering and Technology Management.2 (5).

Paschal, A.O. \& Nizam, I. 2016. Effects of Organisational Culture on Employees Performance: Case of Singapore Telecommunication. International Journal of Accounting \& Business Management. 4(1).

Pradeep, D.D. \& Prabhu, N.R.V. 2011. The Relationship between Effective Leadership and Employee Performance. International Conference on Advancements in Information Technology. 20.

Rahbi, D.A. et al. 2017. The Effects Of Leadership Styles On Team Motivation. Academy of Strategic Management Journal. 16 (2).

Rawung, F.H. 2013. The Effect of Leadership on the Work Motivation of Higher Education Administration Employees (Study at Manado State University). IOSR Journal of Business and Management. 15 (1).

Riva'i, V. 1974. KiatMemimpindalamAbadke-21.Jakarta:MuraiKencana.

Robbins, Stephen P. 1998. Organization BehaviorIn Education Fourth Edition. Jakarta: PT Pos Indonesia.

Robnagel, C.S. 2016. Leadership TodayBusiness and Economics. Switzerland: Springer International Publishing.

Saleh, Akh. Muwafik. (2009). Bekerja dengan Hati Nurani, Erlangga.

Shahzadi, I., et al. 2014. Impact of Employee Motivation on Employee Performance. European Journal of Business and Management. 6 (23).

Suryadi, P. 1999. Kebijakan Kinerja Karyawan, Yogyakarta: BPFE.

Thompson, K. \& Webber, J.K. 2016. Leadership Best Practices And Employee Performance: A Phenomenological Telecommunication Industry Study. Global Journal of Business Research. 10 (1).

Wanjiku, N.A. \& Agusioma, N.L. 2014. Effect of Organisation Culture on Employee Performance in Non Govermental Organizations.International Journal of Scientific and Research Publications.4 (11). 